\title{
PROJECTION METHODS IN CHINESE, KOREAN AND JAPANESE STAR MAPS ${ }^{1}$
}

\author{
KAZUHIKO MIYAJIMA \\ Doshisha University, Kyoto, Japan
}

The celestial map of the Chunyou (淳枯) stone inscription in Suzhou (䉏州) and that contained in the Xin yixiang fayao (新倿象法要), both belonging to the Song (生) Dynasty, are among the oldest of the extant celestial maps in China. The former has a circular form, and the latter is in two forms, circular and rectangular. I have been wondering which projection methods were used in these star maps, or rather, whether they were ever drawn accurately enough for us to be able to discuss their projection methods. While the stone inscription in Suzhou remains original without any change, we are not sure to which extent the star map in the Xin yixiang fayao maintains its original form, because the text underwent frequent reimpressions.

The rectangular celestial map of the Xin yixiang fayao consists of two parts, namely, Hunxiang tongbeifang zhongwaiguan xingtu (渾象東北方中外官星圈, 'the figures of inner and outer bureaus in the east and north on the celestial globe') and Hunxiang xinangfang zhongwaiguan xingtu (渾象西南方中外官星圆, 'the figures of inner and outer bureaus in the west and south on the celestial globe') ${ }^{2}$ The former is drawn on two pages (7 verso and 8 recto) and the latter on the next two pages ( 8 verso and 9 recto). Therefore, the four successive pages cover roughly $12^{h}$ to $18^{h}, 18^{h}$ to $0^{h}, 0^{h}$ to $6^{h}$, and $6^{h}$ to $12^{h}$, respectively. ${ }^{3}$ We call these pages the third, fourth, first, and second quadrant, respectively.

Since the existing text of the Xin yixiang fayao is based on the recension of the Shoushange congshu (守山阔签書), I photocopied a text of this recension belonging to the Research Institute for Humanistic Studies, Kyoto University. I used a macro lens which yields less distortion and took great care so that the optical axis of the camera was perpendicular to the map. I used a negative film of the photograph in order to analyze the projection method and measured the positions of the juxing (距星, determinative stars) in each constellation. I compared the measured positions of the determinative stars with the observational values which are preserved in ancient documents. I used $y=0$ for the equator and $x=0$ for the right edge of each quadrant.

Observations of fixed stars were carried out four times during the Song Dynasty, namely, in the Jingyu (景祐) period (1034-1038), the beginning of the Huangyou (皇祐) period (1049-1054), the Yuanfeng (元晋) period (1078-1085), and the Chongning (掌察) period (1102-1106). We have only a fragment of the record on the first set of observations. As for the last two observations, the records we have are limited to those of difference in right ascension of the twenty-eight lunar lodges (二十八俩). For the second set of observations, however, records of a total of 358 observed stars survive

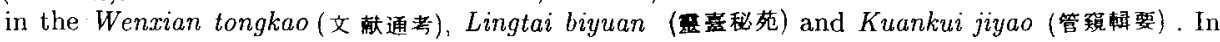
Yabuuti (1) and (2) attempts were made to identify these stars and it was demonstrated that the

\footnotetext{
${ }^{1}$ I have changed the title of this paper for the following reason. I did not have time to analyze the Chunyou stone inscription, but I had a chance of analyzing two celestial maps, one from Japan and the other from Korea. The Japanese one is a rectangular star map in the Tenmon seishö $z u$ (天文成㒀因, 'Map of the arrangement of stars and constellations'), a work of the astronomer Shibukawa Harumi (涉川海) and his son Hisatada (昔), published in 1699;

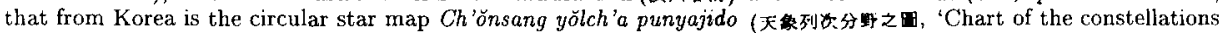
and the regions they govern'), originally engraved on a stone in 1395. As a result of my aralyses I found that the celestial maps in the Chinese cultural area in East Asia were based on the same projection method.

${ }^{2}$ Hun xiang (湾) means celestial globe. The names of the four cardinal directions were used in order to designate the four parts of the wide belt which has a width of about $55^{\circ}$ on both sides of the equator. The starting point of the 'east' is at the first point of jiaoxiu (角楦), i.e. about $12^{h}$, and the remaining directions are counted to the direction of increasing right ascension. The 'inner' and 'outer' mean north and south of the equator, respectively. Following the Chinese tradition of designating constellations after the bureaucracy, the stars and constellations were called guan (官, 'bureau').

${ }^{3}$ The verso pages are a little narrower than the recto pages.
} 
star map in the Xin yixiang fayao was based on the observations carried out during the Yuanfeng period. However, since no observational records from the Yuanfeng period are extant, I had to use the record belonging to the Huangyou period for my present purposes. I converted Chinese degrees into modern degrees by multiplying the former by 0.9856 . Since the values relevant to the right ascension are only give in ruxiudu (入宿度, the distance in right ascension from the determinative stars of the twenty-eight lunar lodges), Yabuuti simply added them to the right ascension of the determinative stars in A.D. 1050 in order to obtain the observational value of the right ascension $(\alpha)$ of each star. I followed the same method, but used the polar distance $\left(p=90^{\circ}-\delta\right)$ instead of the declination $(\delta)$.

There were some difficulties and problems in my analyses, which are summarized as below.

1. Errors might have occurred in the process of transmitting the records of the observational data.

2. In the Xin yixiang fayao it is written that ' 1464 stars are recorded in the map', ${ }^{4}$ but actually only the determinative star of each constellation was observed. It is difficult for us to decide which star in a constellation was determinative. In our sources very ambiguous expressions are used such as 'a star in north-west', or 'a big star'. Sometimes there is more than one star in 'the north-west', and the 'big star' is not always the brightest star in the constellation.

3. Errors might be possible because the observational data I used were not those in the Yuanfeng period, but those in the Huangyou period. Therefore, two types of possible errors must be considered:

- The observational errors of the two sets of records are different. Besides the ordinary observational errors, there might have been errors due to misreading of scales (eg. errors of 10 degrees or those due to the wrong direction of counting) as well as those due to misrecording.

- Different stars might have been observed in the two sets of observations. It is possible that, although the selection of determinative stars had been established, a wrong star was caught in the finder of the sighting tube (望简) of the armillary sphere and was regarded as determinative.

4. There might have been errors which occurred when the original figure was drawn or when they were transferred to printing blocks.

5. Deformation might have occurred at the time of reimpression.

If the result of my analyses is reliable enough, however, we can detect these errors and make corrections, and decide which is the determinative star.

It seems that a cylindrical projection was applied for the rectangular maps. ${ }^{5}$ Thus, for the right ascension, we have a relation of the type: $\alpha=A \cdot x+B$. As for the polar distance, since there are various types of cylindrical projections, different formulas might be possible. For instance, $y=C \cdot \log \tan (p / 2)$, according to Mercator's method, or $\delta=C \cdot y \quad\left(\right.$ i.e. $\left.p=90^{\circ}-C \cdot y\right)$, according to the cylindrical equidistant projection (正距卫筒図法)

I applied the method of least squares for the right ascension of the stars in the third quadrant. The result was:

$$
\alpha=-8.2933 \cdot x+180.23
$$

The constant of this formula represents the right ascension of the right edge of the figure. Although the ecliptic drawn in the star map does not cross the equator at the right edge of the figure, it is evident that this figure was drawn making the autumnal equinox the starting point, since the constant is nearly $180^{\circ}{ }^{6}$

When we express the relation between $y$ and the polar distance $p=90^{\circ}-\delta$ in the graph, the plotted dots are almost on a straight line. In other words, the cylindrical equidistant projection must have been used. When we compute the coefficient of a formula of the type $p=C \cdot y+D$ by means of the method of least squares, we obtain

$$
p=-8.0030 \cdot y+89.91 \text {. }
$$

\footnotetext{
${ }^{4}$ In fact the number is 1463 , because one star was dropped by mistake.

${ }^{5}$ In other words, the azimuthal projection method like central projection or stereographic projection was not used.

${ }^{6}$ The right ascension of the left edge of the figure turned out to be $261.82^{\circ}$. The reason that this is less than $270^{\circ}$ is that the horizontal length of the figure in the right hand page (verso) is shorter than the figure in the left hand page (recto), because Chinese characters are placed at the right edge of the right hand page.
} 
The fact that the constant of this formula, i.e. the polar distance of the equator, is very close to $90^{\circ}$ means that this figure was drawn accurately. The upper edge of the figure turns out to be $33.49^{\circ}$, which is slightly less than the latitude of Kaifeng (開封). This means that the figure was drawn northward to the circle of constant visibility and a little further. In the case of the circular celestial maps, the drawing is made outward to the constant visibility circle and a little exterior. Thus they must have been made in such a way that the two areas slightly overlapped each other. ${ }^{7}$

I applied the same method to the other quadrants and found that the errors in them are slightly larger than those in the third quadrant. Nevertheless, the results were rather consistent.

The circular celestial map in the Xin yixiang fayao ${ }^{8}$ is divided into a right half and a left half which are drawn on two separate pages. If the circular map was drawn by the azimuthal equidistant projection the polar distance $p$ must be proportional to the distance $r$ from the center of the figure. If, on the other hand, it were drawn by a stereographic projection, as in the Hellenistic period, a relation such as $p=2 \cdot \arctan (r / A)$ should have been assumed. When I plotted the relation between the measured values and the polar distances, I found that they formed nearly a straight line. Therefore I concluded that the azimuthal equidistant projection was used in this map.

But there remain some problems. For example, the horizontal radius and the vertical radius are not equal. This means that the center of the figure is not necessarily the center of mapping (the north pole). So I thought it necessary to compute the coordinates $\left(x_{0}, y_{0}\right)$ of the north pole in comparison to the center temporarily set at the time of measurement. Assuming that the relation is not proportional but a constant value is involved, and that the distance from the center can be expressed by the formula like $p=A \cdot r+B$, I applied the method of least squares. As a result I found that all the values $x_{0}, y_{0}$, and $\mathrm{B}$ are close to zero and, therefore, that the map was drawn by azimuthal equidistant projection rather accurately.

I have compared the positions of stars measured in the figure with the positions expected from the observational data in the literature. Even though we admit that the figure was drawn rather accurately, we notice a considerable number of errors. This is probably due to frequent reimpressions. Compared with these maps, the Tenmon seishō zu, based on Shibukawa Harumi's observation and published by his son, is quite accurate. This is because the printing block was original. When we plot in a graph the relation between the polar distance and the $y$ coordinate position, the scarcity of dispersions supports my assumption. The recorded position and the observed position agree quite well ${ }^{9}$. These observational values are recorded in Shibukawa's Tenmon keito (天文統) and they were studied in Watanabe (3) and (4).

In the case of the Korean circular celestial map (天象列次分野之図), I used theoretically computed values, since no observational data were available. Although it was difficult to select the determinative star, the result of the comparison was considerably good. Therefore we can say that azimuthal equidistant projection was used in the Korean map.

From these we can conclude:

(1) Needham's interpretation of the projection method of the Xin yixiang fayao as Mercator's projection is wrong.

(2) The most Western star maps before modern times are circular and they are based on stereographic projection. This method is quite geometrical, while the star maps in the Chinese cultural area are based on 'numerical projection'. Thus we can say that the different projection methods reflect the difference in character of astronomy and mathematics.

(3) The star maps in China, Korea and Japan appear as if they were drawn without good care, but, in fact, they can be analyzed quantitatively. Some of the star maps, in particular, retain the original accuracy even after frequent reimpressions as in the case of the Xin yixian fayao.

(4) This analysis is applicable only to the determinative stars, but the result which I obtained through this study will give some help for the identification of the other stars in Chinese constellations.

\footnotetext{
${ }^{7}$ The coefficients of $x$ and $y$ are of course variable according to the size of the figure. The values shown here are those in the negative film.

${ }^{8}$ There are two kinds of maps, one is only around the north pole and the other is around both the north pole and the south pole making the equator outermost circle. I made my analyses of the first type only.

${ }^{9}$ I followed Shibukawa's identification in the present research, although there are several differences from the identifications in the Yixiang kaocheng 保争考成 and Yabuuti's paper.
} 
(5) The determinative stars are mostly located near the western end of constellations, but sometimes they are in other places. Sometimes they are less bright. We do not know what criterion was used for the selection. The distribution of the determinative stars in the Xin yixiang fayao shows that there are many cases where the determinative stars are aligned vertically, that is, stars with approximately the same right ascension were chosen. This is probably for the sake of effectiveness of observation -- one has only to move the sighting tube along the north-south direction with less motion in the east-west direction.

\section{References}

1. Yabuuti, Kiyosi (整内清): 'Sōdai no Seishuku' (宋代の星宿\}, Tōhō gakuhō, Kyoto, Vol.7, 1936.

2. Yabuuti, Kiyosi: Chūgoku no tenmon rekihō (中国の天女暦洼), Tokyo (Heibonsha), 1969.

3. Watanabe, Toshio (碳边敏夹): 'A Report on Yasui Harumi's star map' (保讲春海星图考)， Journal of the University of Mercantile Marine (Natural Science), Vol. 14 (1963).

4. Watanabe, Toshio: A History of Modern Japanese Astronomy (近世日本天文学史), Vol. 2, Kōseisha Kōseikaku, 1987.

5. J.Needham: Science and Civilisation in China, Vol. 3, Cambridge Univ. Press,1959.

6. Pan Nai (潘) \& Wang De-chang (王德昌): 'The Star Observation at Northern Song Dynasty and Hunag You Star Catalogue' (北柂的恒星観測及《泉裙星表》上)，『科技史文集』，第 10 軲，]983

7. Pan Nai: 『中国恒星観測史』学林出版社, 1989. 